\title{
LITERATURA DEL DERECHO: ENTRE LA CIENCIA JURÍDICA Y LA CRÍTICA LITERATURA
}

\section{LEONOR SUÁREZ LLANOS ${ }^{1}$}

\begin{abstract}
RESUMEN: Este trabajo indaga en la relación entre el Derecho - reglas, poder, fuerza y seguridad jurídica - y la literatura - abierta, dúctil, revulsiva del "tener que" y soñadora de lo que "podría deber ser". Para ésta, instrumento posmoderno del reconocimiento del otro y sus diferencias, el Derecho ha forzado las historias de las personas reales y sus anhelos de justicia en conceptos imparciales silenciándolos, especialmente los de los más vulnerables. Aquí empezaré analizando qué es, dónde, cómo y por qué apareció el Law and Literature Movement, y recordaré sus tres dimensiones del Derecho de/como/en la literatura para centrarme en estas dos últimas estrategias de análisis. A partir de ahí profundizaré en la interpretación, la posición y función del intérprete, la retórica, la narrativa y el New Criticism como formas de análisis literario del Derecho. Y llegaré a unas conclusiones que se asientan sobre siete objeciones al planteamiento literario (a su justicia, su antiformalismo, sus presuntas virtudes judiciales, a la irracionalidad de la empatía, a su teoría crítica literaria y a la propuesta de la novela en cadena prospección de la dinámica del Derecho, a su contextualización y a los riesgos de la emoción y la empatía para los derechos y la seguridad jurídica) y las respuestas posibles a esas objeciones. Unas conclusiones que nos abren a un proyecto ilusionante pero que, eso sí, impone ser especialmente exigentes en el manejo integrado de una literatura transgresora de los límites de una realidad compleja, dinámica y manejable del Derecho.
\end{abstract}

Palabras Clave: derecho; literatura; justicia; empatía; racionalidade; interpretación; argumentación; deconstrucción; vulnerabilidad.

\section{INTRODUCCIÓN}

Desde hace décadas, el Derecho se desarrolla en capítulos de crisis y renovaciones sucesivas, en amplia medida, dicen los críticos, impulsadas porque el formalismo del iuspositivismo ortodoxo es marca de la incapacidad y/o desinterés del Derecho, del teórico, del dogmático, y de sus jueces por hablar de la virtud y por hacer justicia para las personas reales.

1 Doctora en Derecho. Profesora titular de Filosofía del Derecho en la Facultad de Derecho de la Universidad de Oviedo. Oviedo, España. E-mail: leonor@uniovi.es. 
Y es en este punto en el que entra en juego todo el instrumental crítico de la literatura en relación con el Derecho. Una propuesta que en diversos ámbitos y con objetivos varios impulsa nuevas perspectivas deconstructivas y/o reconstructivas de gran interés afiliadas a esquemas racionales muy alejados de la razón universal que kantianamente adoptó la modernidad hasta convertirla, con Descartes, en un presupuesto existencial.

Es frecuente que los trabajos sobre Derecho y literatura comiencen proponiendo un texto literario en torno al que se desarrollan distintas interpretaciones críticas del Derecho y la justicia. Se trata de una metodología muy interesante y refrescante que, sin embargo, no es la que seguiré en este trabajo. Precisamente porque lo que me cuestiono es la posibilidad y adecuación de tal método y de la relación sustantiva que presupone entre el Derecho y la literatura.

A tal efecto, partiré de la siguiente premisa, más o menos inocente: que el Derecho crea ficciones sociales que son jurídicamente reales (ciudadanos, extranjeros, sociedad, nación, diligencia debida, responsabilidad objetiva, etc.). Y que ese Derecho está constitutivamente plagado de historias escritas por legisladores, jueces y letrados sobre buenos y malos, sobre las razones para tener razón, sobre el poder y la vulnerabilidad, la familia, la educación y la salud, la vida y la muerte, el indulto y el perdón, etc. Son historias encapsuladas en normas que se realizan para un lector que cualquier día, queriéndolo (p.ej., contrato) o sin querer (p.ej., acusación penal), se hace personaje del caso que novelan (Calvo, 2016).

La encapsulación de esas historias en normas, y todo su tratamiento iuspositivo posterior, se ha conformado en la modernidad en torno a la certeza, la seguridad y la imparcialidad que responden, a su vez, al afán de positivización del Derecho que alcanzó su punto álgido, formalizador y cientifista en la primera mitad del siglo XX en un contexto de victoria $\mathrm{y}$ poder del formalismo científico en todos los ámbitos. Ahora, todo lo que el jurista puede hacer por el Derecho es objetivarlo, formalizarlo, completarlo, ponerlo al servicio de intereses asépticos e impersonales y no divagar acerca de lo que debería ser pero no es, entre otras cosas, piensa el iuspositivista, porque las concepciones sustantivas de lo justo han dado sobradas 
muestras de sus mutuos desacuerdos y de las diversas formas de terror de que son capaces.

Pero formalizar es también problemático, responde el crítico. Porque conduce a un abismal reino sobreinstitucionalizado ajeno a la justicia y las necesidades de las personas reales.

Por eso, frente a ese Derecho se yergue una literatura dispuesta a afrontar con mejor perspectiva los muchos problemas de los que ese Derecho se resiente. Porque ella es abierta, dúctil, incierta, soñadora y buscadora de representaciones imaginarias que abren un presente más atractivo, más justo y mejor. Es revulsiva de identidades prestablecidas, de las convenciones, de reglas y codificaciones, del "tener que". Y es anhelante de todo aquello que "podría deber ser", de la capacidad creadora, crítica, de libertad, de justicia (Silva, Mourão, 2016, p. 360-361), mientras que el Derecho es el reino del "deber ser" - la norma como autoridad, como fuerza, como obligación. La literatura es la pluma de la razón y los sentidos frente a la espada del Derecho (Ost, 2006, p. 334 et seq.).

Tal es el punto de partida de la crítica literaria del Derecho y de su inicial precursor, el Law and Literature Movement: el Derecho no es un elemento accesorio en la vida de cada cual, sino parte fundamental de lo que somos, pretendemos, hacemos, jugamos, practicamos, exigimos, damos, vivimos y pensamos. Al analizarlo a través de fórmulas lógicas, esquemas trascendentales, dogmas pseudocientíficos, axiomas pretendidamente neutrales y avalorativos, o criterios microeconómicos y de eficiencia se desvirtúa su esencia, naturaleza y función y se aleja de los sujetos reales a los que va dirigido, especialmente de los más vulnerables y necesitados de protección. Ni el método iuspositivista es apropiado, ni el objeto a conocer, el Derecho, existe como una realidad objetiva, pétrea y científicamente analizable, ni el sujeto que conoce participa de una asepsia epistemológica que le permita desentrañar de forma demostrable y predecible el objeto a conocer y las soluciones a los problemas que trata de solventar.

Pues bien, lo que me gustaría plantear como eje en torno al que gire la argumentación y las conclusiones de este análisis es lo siguiente: en amplia medida, lo que decimos que es el Derecho depende de los instrumentos de análisis que se empleen ¿̇Tiene razón la crítica literaria cuando sostiene que si utilizamos una epistemología formalista y neutralizadora los resultados 
serán distintos $\mathrm{y}$ peores que cuando concretamos, reconstruimos $\mathrm{y}$ manejamos el Derecho con y a través de la literatura?

Desde luego, el asunto no es baladí. E incide en uno de los problemas epistemológicos centrales del iuspositivismo, a saber, que aunque pretende ser descriptivo, al describir la normatividad, la descripción se hace normativa, coactiva, institucional y válida de las condiciones descritas. En tanto éstas remiten a la generalidad y a desatender la in/justicia de la norma a efectos de su validez y consistencia, el resultado es que la descripción del deber se convierte en un debemos desatender los sentimientos particulares y las aspiraciones concretas de justicia.

No es éste el lugar para desarrollar los problemas epistemológicos iuspositivistas, ni sus escollos a la hora de justificar que el objeto a describir como Derecho sea seleccionado como tal con carácter previo a su concreción cuando, quizá, debería ser a la inversa, lo que generaría una "falacia iuspositivista", pues cuando la teoría selecciona al objeto a describir como Derecho ya está definiendo lo que es Derecho frente a todo lo demás que deja de serlo, potenciándose la fuerza constitutiva de la teoría, de la dogmática y del silogismo sobre la práctica...

Creo que aquí nos basta con recordar esas dificultades para entender que proponer la literatura como instrumento de "re-conocimiento" del Derecho trae varias cuestiones previas.

Y quizá la primera es la que urge a la literatura a explicitar qué conoce del Derecho y cómo, y con qué límites y garantías de certeza y/o de certidumbre lo conoce.

Pues bien. La premisa literaria es que el Derecho no es un objeto físico o lógico formal susceptible de ser descubierto en términos de demostrabilidad y predicibilidad. El Derecho es narración. Por eso, la literatura es la vía apropiada para conocerlo y reconstruirlo. Porque cuando nos referimos a él, igual que cuando narramos cualquier historias las causas se convierten en razones y la verdad representacional y verificable se transforma en "verosimilitud".

En efecto, en el Derecho y en el relato literario lo argumentable no es su interpretación, sino ellos mismos, pues sus mismos hechos se reconstruyen idealmente conforme a objetivos retóricamente maleables (Bruner, 1991, p. 5-15) por los sentimientos de amor, odio, terror... que nos 
suscitan. Luego el Derecho los periclita, los mutila, para volverlos predecibles, manejables, asumibles y luego necesarios para poder proclamar, por seguridad, sus consecuencias (Craft, 1992, p. 521 et seq.).

Pero, si esto es así, si lo que conocemos es el relato literario y las pruebas son de convicción emocional, empatía sentimental y justicia heroica y colosal, claro, surgen varias cuestiones, algunas capitales, p.ej., ¿cuándo y por qué la teoría del conocer objetivo se hace literaria? ¿Es el Derecho también literatura o es solo que puede convertirse en narración literaria? ¿Participa la literatura de normatividad y criterios autónomos de autoridad? ¿Debemos sustituir la justicia imparcial por los argumentos ad hominem y sentimientos particulares? ¿O solo vale la literatura centrada en el Derecho previamente caracterizado como razonable, legítimo y justo?

Pues bien, para ir desgranando las respuestas a estas cuestiones, y así fijar los márgenes de la relación del Derecho con la literatura, asentaré el punto de partida del análisis en el crítico y refrescante Law and Literature Movement y sus sucesivos desarrollos, a fin de valorar los presupuestos, objetivos y posibilidades que las perspectivas literarias ofrecen al Derecho.

\section{EL MOVIMIENTO LAW AND LITERATURE: DÓNDE Y CUÁNDO SURGE Y POR QUÉ}

El Law and Literature Movement surge en los EEUU en los 70ss - la publicación de The Legal Imagination, de Boyd White, formaliza en 1973 su fecha de inicio ${ }^{2}$ - y se desarrolla ampliamente en los 8oss, que es cuando el análisis literario del Derecho se convierte en un movimiento crítico del Derecho más o menos ordenado y representativo. A partir de ahí se suceden diversos desarrollos especialmente en el ámbito estadounidense donde el análisis literario del Derecho, por su cuenta o en conjunción con distintas

2 Aunque hay prolegómenos desde comienzos del s. XX. En 1908 Wigmore elabora $A$ List of Legal Novels, cien, con temática jurídica, y pide a los juristas que atiendan a los trabajos de ficción significativos para el Derecho. En 1925, Cardozo publica Law and Literature, y propone interpretar las sentencias como ejemplos literarios y estructurar las pretensiones retóricas de los tribunales (Cardozo, 1931). En Europa, en los 30ss, Fehr, D'Amato o Radbruch, este último sobre Tolstoi, Flaubert o Dickens, demuestran su interés jurídico por la literatura. En 1947 y en EEUU, Fuller publica Law in Action, analizando los asuntos jurídicos a partir de muy diversa literatura. Y entre nosotros Ossorio Morales publica, 1949, Derecho y Literatura, usando los clásicos de la literatura castellana para analizar la praxis jurídica y social del Siglo de Oro. En los 50ss se fortalece el análisis literario del proceso penal, los errores judiciales, la justificación de la pena, etc. Y en los 6oss, en EEUU se publica el primer volumen The World of Law, Law and Literature, analizando casos muy diversos a través de las obras de James, Zola, Wilde, Melville, Swift, Camus, etc. 
disciplinas críticas vinculadas a la raza, género, etc., es parte de muchos de los programas universitarios de formación33.

Realmente, no es extraño que, por varias razones, el movimiento jurídico literario tenga más éxito en el ámbito sajón y en EEUU. Por mencionar algunas de esas razones.

Una, porque su caldo el cultivo es la vertiente postestructuralista de los CLS, p.ej., Drucilla Cornell o Jack Balkin, quienes, con gran influencia, entre otros, de Derrida, apartan la interpretación constitucional del intencionalismo y el estructuralismo4.

Otra razón. Porque el detonante, por negación, del nacimiento institucional del movimiento jurídico literario es la aparición de la formalista e instrumental Economics Theory of Law que apadrina Posner y que tiene su origen y centro de desarrollo en EEUU en los 70ss.

Tercera razón. Porque es destacadamente en los EEUU donde se han desarrollado los estudios culturales críticos del Derecho - de raza, género, clase, orientación... - para los que el Law and Literature Movement ofrece instrumentos crítico-retóricos especialmente útiles a la búsqueda culturalmente significativa de la identidad que interesa a esos cultural studies of Law.

Y, cuarta razón. Porque, al menos en principio, es más fácil comprender el planteamiento literario desde una mentalidad jurídica de conocimiento open book y de jueces constructores de políticas públicas 5 que desde el dogmatismo eurocontinental y su fe en una racionalidad científica que ordena los saberes y monitoriza las soluciones silogísticas.

3 Así, la literatura es parte esencial del análisis del Derecho en muchas universidades estadounidenses. "Derecho y literatura", por una parte, figura en el programa de más del 40\% de las universidades americanas. Vid. A. K. Trindade y R. M. Gubert (2009). Por otra parte, cuenta con revistas especializadas (entre otras, 'Law and Literature', en http://ucpressjournlas.com/journal.php?j=lal). Y, además, el vínculo entre Derecho y literatura se fortalece con distintas asignaturas que profundizan en el crimen y la pena p.ej., "Crime, Law, and Literature at the Law School" (Chicago Law School) - o en otras críticas concretas, p.ej., "Time and Law", que analiza el impacto del factor tiempo en la decisión jurídica, o "Race \& Politics: Postmoderno Racial? A 21sr Century Query", sobre los fracasos de los derechos civiles de los no-blancos (ambas de la Harvard Law School).

4 En este contexto y en torno a este eje postestructuralista se celebraron a comienzos de los 8oss importantes encuentros académicos, p.ej., en las Universidades del Sur de California o de Texas; en esta última Texas lo abría Sanford Levenson con su conferencia "Law and Literature" vinculando la interpretación judicial a la práctica creativa de la interpretación literaria descritas por teóricos de la literatura como Stanley Fish y Harold Bloom.

5 Insiste y desarrolla este aspecto Zolezzi Ibárcena (2013, p. 384-386; 407). 


\section{LAS PROYECCIONES DE ANÁLISIS DEL MOVIMIENTO DEL DERECHO Y LA LITERATURA}

En general, hay un acuerdo bastante generalizado sobre la articulación del vínculo entre el Derecho y la literatura en torno a la taxonomía de Posner (1988) de tres categorías: el "Derecho en la literatura"; el "Derecho como literatura" (versión fuerte); el "Derecho de la literatura”.

De ellas, la que menos interesa aquí es la del Derecho de la literatura; la regulación jurídica de la actividad literaria, derechos de autor, producción, distribución, límites a la libertad de expresión, in/moralidad literaria, pornografía, etc. Aunque esto no supone degradar su relevancia. Pues la historia regulativa de lo literario es la historia de la censura, de las mentalidades sociales, de la libertad, el paternalismo, las tradiciones morales y las dictaduras ${ }^{6}$.

Pero me suscita más interés el Derecho en la literatura, atento a los textos literarios que plantean problemas jurídicos y políticos. Y el Derecho como literatura, que interpreta el Derecho con instrumentos literarios, narrativos, de interpretación imaginativa, hermenéutica y retórica.

\subsection{El derecho en la literatura}

Trata de obtener rendimiento de la literatura cuando ésta se ocupa de cuestiones de importancia capital para el Derecho: igualdad, derechos de las minorías, justicia, justificación del castigo, distribución de la riqueza, justificación del poder, el paternalismo estatal, etc. ${ }^{7}$ Porque la literatura ofrecería al Derecho y al análisis jurídico una perspectiva privilegiada de las normas, la sociedad, los valores, las instituciones jurídicas y los juristas.

$6 \quad \mathrm{Al}$ respecto y comp. atiéndase al interesante análisis de Posner (1988, p. 319 et seq.). También a la revisión civil, penal y constitucional que a tal efecto ofrece María José Falcón y Tella (2015, p. 17-47).

7 Pensemos en Antígona, Tiempos Difíciles, Crimen y Castigo, El extranjero, La citación, Causa justa, El mercader de Venecia, El Conde de Montecristo, Cumbres Borrascosas, Los Hermanos Karamazov, El Proceso, Un Mundo Feliz, La Naranja Mecánica, El informe pelícano, Billy Bud, marinero; Rebelión en la granja, 1984, La Caída, A sangre fría, Matar a un ruiseñor, El hombre que quería ser culpable, Anatomia de un asesinato, El viaje del profesor Caritat... En este contexto, Falcón y Tella (2015, p. 61 et seq.) revisa la proyección jurídico-crítica de representativas obras literarias de la Edad Antigua, Media, Moderna y Contemporánea. Tmb. Talavera (2006, p. 61 et seq.) con La Alianza del Sinaí, frente al "contrato social" (cap. 2), Antígona, sobre justicia y autoridad (cap. 3), El Mercader de Venecia, el derecho positivo y el valor de la interpretación justa (cap. 4), El Proceso, crítica a la concepción formalista y avalorativa del Derecho (cap. 5) y Rebelión en la Granja, sometimiento del Derecho al poder y la política. 
Aún en este nivel del Derecho en la literatura podemos diferenciar dos versiones. Una que sí me interesa más y otra, nuevamente, que no tanto.

La que no me interesa demasiado aquí, a pesar de su gran relevancia instrumental, es la que propone a la literatura como instrumento o recurso metodológico o pedagógico que facilita la enseñanza del Derecho. $Y$ es que el conocimiento del Derecho se puede transmitir de forma mucho más amena, entretenida, espiritual, artística, visual, cercana, íntima, etc., gracias a la literatura ${ }^{8}$. Se trata, pues, de una cuestión de metodología pedagógica muy interesante 9 y que debería ser impulsada junto y frente a otras alternativas tradicionales del conocer. Aunque en sí no cuestiona ni parámetros de racionalidad ni contenidos sustantivos. El mismo Posner, representativo testigo crítico del Law and Literature Movement, reconoce, ensalza y reclama la utilidad educativa de la literatura para impulsar las técnicas de elocuencia y persuasión y hacer más memorable, atractivo y amable el estudio el Derecho y de muchos de sus problemas filosóficos y de fundamentación y sus dialécticas (derecho natural/positivo, la ley general/equidad, venganza/pena y sanción jurídica). Aunque también insiste en frenar las aspiraciones literarias frente al Derecho ${ }^{10}$.

Esta última advertencia es una buena excusa para introducirnos ya en otros ámbitos que van mucho más allá del soporte didáctico. Pues, la otra dimensión del Derecho en la literatura, y ésta aquí me interesa más, indaga en valores jurídicos esenciales como la igualdad, la justicia, la responsabilidad, la libertad, los derechos, etc.

Se trata de la visión "moralizante", “edificante" (Posner, 1988, p. 306307) del movimiento del Derecho y la literatura. Su estrategia es analizar y comparar los textos legales y literarios para esclarecer aspectos importantes de la teorización y práctica del Derecho y de su justicia. Y sus dimensiones son varias; entre ellas: la recreación crítica de procesos difíciles y complejos, como puede ser el indiciario y probatorio como Doce Hombre sin Piedad o

8 En efecto, estudiar el Derecho con la literatura es muy formativo, entre otras cosas, porque "la Literatura y el cine son más divertidos que la práctica judicial..." (Díez Gargari, 2008, p. 164-165).

9 P.ej., y con sus materiales en acción (Bonorino, 2011, p. 73 et seq.). Cfr. Rios (2005, p. 218).

10 Pues el Derecho es el conjunto de sus ficciones legales y sus formalismos - derechos, igualdad ante la ley, cosa juzgada, etc.-, y la literatura sólo puede tratarlo como un elemento metafórico que no aporta al jurista conocimiento jurídico serio (Posner, 1988, p. 358-360; 275-289; 353 et seq.). Cfr. Calvo (2015, p. 699). 
Causa Justa, o tantas otras obras literarias. La descripción y cuestionamiento del modelo standard de jurista ${ }^{11}$, p.ej., La Citación, El Bufete. La emotividad, la ideología, la simbología asociada al Derecho, su autoridad, su capacidad liberadora u opresiva, etc. El Hombre que quería ser culpable, 1984, Zamiatin..., p.ej., recrean esas valoraciones sociales contextualizadas retando al lector al planteamiento crítico. La proyección crítica del trato que da el Derecho a los grupos oprimidos y vulnerables (por raza, género, cultura...). Y, finalmente, el valor esencial de la justicia en sus distintas manifestaciones y contextos, como Billy Bud, La Luz que no Puedes Ver...

Pues bien, la esencia de la apuesta moralizante, edificante del Derecho en la literatura, es que los valores morales que destila la literatura ayudan a los jueces a solventar dilemas éticos ${ }^{12} \mathrm{y}$ al jurista, en general, a volverse más fundamentadamente crítico al ampliar sus horizontes referenciales (Freitas, 2002, p. 5; Silva, 2001, p. 122-123), abrir perspectivas de mundos alternativos al tradicional, y reconocer la complejidad de las formas de vida, las decisiones, los sentimientos y el imaginario social - político, religioso, económico, valorativo,...- y la tensión entre conceptos formales y éticos (Posner, 1988, p. 354-356).

$\mathrm{Y}$ tal es la afirmación de principio y fundamental de la paradigmática Poetic Justice de Martha Nussbaum: que la imaginación literaria es básica para la justicia y, en consecuencia, para una ciudadanía libre, para la democracia, para la igualdad, para la humanización del otro, para convertirnos en jueces incorporados en espectadores juiciosos. Porque "leer

11 Sus modos de ser y actuar que, p.ej., Weisberg, uno de los padres del movimiento del Derecho y la literatura, proyecta sobre tres dimensiones de análisis generalmente tan destacadas por la literatura como olvidadas por el análisis jurídico. El modo en el que se comunican los juristas, cómo narran y construyen sus discursos y cómo la brillantez puede ocultar planteamientos éticos muy dudosos. El modo en que los juristas se relacionan con quienes están fuera de las estructuras del poder. Así, El Extranjero, refiere precisamente el modo de tratar a quien está fuera del sistema político jurídico mismo. Y el modo en que razonan y sienten los juristas. Su manipulación, su elitismo y aislamiento, su carácter receloso, su relativismo ético a la hora de realizar su actividad profesional, su frugalidad, su distanciamiento del sufrimiento ajeno, su ambición, corrupción, predominio o altruismo.

12 Como "[l]a literatura nos ayuda a comprender al otro... a simpatizar con su pena,... a compartir su arrepentimiento, y... a celebrar su alegría, nos hace más morales, nos hace mejores" (White, 1985b, p. xi). Cf. White (1973, 1990, 2000). Por eso, "[l]os trabajos sustantivos de la literatura pueden ayudar a comprender los principios constitucionales al ilustrar de forma penetrante las formas de problemas personales que deberían ser reconocidos como controversias universales" (Hayman; Levit; Delgado, 2002, p. 462). 
novelas desarrolla capacidades morales sin las que los ciudadanos no conseguirían hacer realidad las conclusiones normativas de cualquier teoría moral o política, por excelente que sea" (Nussbaum, 1995, 17).

Para Nussbaum, filósofa, no jurista, y personaje fundamental del Law and Literature Movement y su propuesta ética y de justicia, todo asunto filosófico y del conocer implica un diálogo interdisciplinar con la sociología, la economía, la política, el Derecho... y la literatura.

De esta literatura destaca Nussbaum la idoneidad del realismo (angloamericano) para dar cuenta de "formas persistentes de necesidad y deseos humanos encarnados en situaciones sociales concretas”. En particular, en relación con el Derecho y la política, Nussbaum, a través del análisis de Hard Times de Dickens, se enfrenta tanto al Law and Economic Movement y al basamento economicista y utilitarista de la elección racional del Derecho moderno, al que solo interesa el dato individual como parte de una operación matemática ajena a las emociones de las personas ${ }^{13}$. Cuanto al relativismo nihilista, p.ej., de Stanley Fish (1980, 1982, 1983, 1987a).

Ambos incurrirían en graves errores. Porque es imprescindible jugar con la fantasía (Nussbaum, 1995, p. 39 et seq.) y la imaginación (Nussbaum, 1995, p. 25 et seq.) e indagar en el misterio y complejidad de cada vida, en sus emociones (Nussbaum, 1995, p. 85 et seq.), miedos, traumas, frustraciones y en el dolor y la perplejidad frente a las elecciones y las dificultades. La literatura, la novela, nos permite acceder a la singularidad y los matices y peculiaridades del mundo de la vida y ser empáticos con el otro, colocarnos en su lugar, sentir compasión y comprender y compartir sus emociones dolorosas en clave de dignidad humana. Y es que solo la emoción permite materializar la solidaridad social frente a una humanidad común favoreciendo un comportamiento ético (Nussbaum, 1995, p. 18; 45) y un paradigma racional y moral de comprensión y razonamiento moral centrado en lo particular del contexto pero sin caer en relativismos.

13 En eso falla el movimiento y "también falla Dickens al no percatarse de los daños causados a la autonomía de las mujeres por las desigualdades endémicas al matrimonio que se vivían en su tiempo" (Nussbaum, 1995, p. 45). 
Planteamiento que adquiere especial relevancia en relación con el razonamiento judicial al significar que la literatura contribuye a desarrollar una suerte de capacidades que favorecen una respuesta emocional y racionalmente más adecuada al caso ${ }^{14}$.

Es aquí donde Nussbaum (1995, p. 138-159) insiste en la figura del "juez literario".

Aquel que, además de su formación científica sabe acomodar las reglas a la complejidad de los contextos reales y enfrentarse a valores concretos al comprender la vida con la imaginación del novelista. Y, además, comprende mejor los hechos en cuanto incidentes insertos en valoraciones y respecto de los que no solo se disputa lo que sucede, sino también su "significado humano - cuán intimidantes..., cómo afectaron... [...]" (Nussbaum, 1995, p. 148) para el Derecho los incidentes que se juzgan ${ }^{15}$. Lo ejemplifica en Poetic Justice revisando, entre otras, la sentencia Bowers vs Hardwick y los dictámenes de los jueces White y Burger.

Si bien, reiteradamente insiste Nussbaum en que "el juicio literario no es suficiente para juzgar bien y resultaría pernicioso si no estuviera restringido por otras virtudes puramente institucionales y judiciales...” -, y aquí le parece que se equivoca Whitman cuando niega los límites institucionales del rol judicial. Así, no se trata de sustituir el razonamiento jurídico de la aplicación de reglas por un razonamiento particularista ${ }^{16}$, ni de que la emoción y la empatía sean todo lo que el juez necesita para

14 Así, muchos insisten en que la literatura abre al jurista al "conocimiento de las interioridades de la psiquis humana y la influencia del entorno en las actividades de los individuos" (Zolezzi Ibárcena, 2013, p. 379; 386 et seq.).

15 Interesantísima cuestión tantas veces apartada del análisis del Derecho y que Nussbaum desarrolla de forma atractiva analizando, precisamente, la argumentación del juez Posner en los "Poetas como jueces", que luego recoge en Poetic Justice. Se enjuiciaba la acusación de acoso sexual de una mujer, la única de un grupo de trabajadores, chapistas, varones. El desarrollo pormenorizado de los hechos, la utilización de figuras literarias y retóricas, la profundización en los sentimientos de injusticia, desigualdad, desamparo, etc. de la demandante que procura Posner, arrojan una luz distinta a la acusación que permite entender materialmente qué significa la asimetría en la relación laboral más allá de los términos y su semántica neutralizada. Se comprende emocionalmente la dureza de la ofensa colectiva, insistentey sostenida en el tiempo. Y, así, se puede visualizar y sentir la desprotección que una gran empresa no consigue atajar una absoluta injusticia librada sobre una sola mujer.

16 "[S]ería extremadamente peligroso sugerir que el razonamiento moral regido por reglas sea reemplazado por la imaginación empática... Defiendo la imaginación literaria porque me parece un ingrediente esencial de una postura ética que nos insta a interesarnos por el bienestar de personas cuyas vidas están distantes de la nuestra. [Pero e]sta postura ética deja amplio margen para las reglas y los procedimientos formales" (Nussbaum, 1995, p. 18). 
resolver sus $\operatorname{casos}^{17}$. Diversamente. Los límites institucionales, las capacidades técnico-legales y el conocimiento de la historia, del Derecho y sus precedentes son fundamentales. Si bien, para ser plenamente racionales, entiende Nussbaum, los jueces deben ser capaces de fantasear y hacer jugar la imaginación literaria, favoreciendo la empatía y la concepción humanística del razonamiento jurídico que permite superar el razonamiento científico técnico y su obtusa imparcialidad (Nussbaum, 1995, p. 121).

Un afán moralizante y edificante que indaga en la literatura para buscar la justicia y las virtudes del Derecho, y que con tanta maestría desarrolla Nussbaum, que es perseguido ya como un objetivo generalizado por toda la concepción de la literatura en el Derecho (Hayman, Levit, Delgado, 2002, p. 463).

Citaré aquí, entre otros, a Robin West, para quien la literatura debe servir para la reconstitución política y ética de las comunidades al ofrecernos una "crítica legal humanista" que nos vuelve mejores, más morales y "civilizados" gracias a la emoción, la simpatía y la empatía que condonan el dilema ético del odio, la despreocupación por el otro, la violencia y el terrorismo. La literatura permite adquirir una perspectiva crítica externa a la narración del Derecho que trasciende las pautas que lo vuelven autoinmune a la autocrítica al permitir hablar a los personajes oprimidos, los que están fueran de la economía prevalente y el poder establecido. Por eso la narración literaria ofrece los recursos necesarios para reinterpretar el Derecho como un contexto interactivo de relaciones que recorren todas nuestras esferas de interés definición y emoción ocultadas por el modelo moderno de racionalidad (West, 1988a, p. 867 et seq.; 1988b, p. 146, 129 et seq.).

No podemos pensar simplemente que las leyes son "textos" que dan cuenta de nuestras tradiciones e ideales culturales; son instrumentos interactivos de violencia, violación, compasión o respeto y tienen "un gran impacto en la subjetividad de las personas, de los niños, de los esclavos, de las mujeres y del resto de los seres vivos... A menos que aprendamos a sentir, a empatizar con el resto y a asumir esos efectos, no conseguiremos

17 "[I]nsisto en que el razonamiento legal técnico, el conocimiento el Derecho y de los límites del precedente juegan un rol central en el buen juicio y marcan los límites dentro de los que la imaginación debe trabajar" (Nussbaum, 1995, p. 148). 
tener una interpretación decente de los textos legales" (West, 1988b, p. 155). Y la literatura sí sirve para esto, gracias a la contraposición metafórica entre el "hombre económico" y la "mujer literaria" (West, 1988a, p. 867 et seq.) con todas las referencias postkantianas, de género, cuidado y contextualización que la propuesta posmoderna de la narrativa jurídica de West contiene ${ }^{18}$.

Por su parte, el emblemático Rorty reclama sustituir la Filosofía y la ciencia del Derecho por la literatura, convencido como está del enorme potencial transformador y de impulso de la evolución de los sistemas de organización social que tiene la literatura (Rorty, 2002, p. 95 et seq.; Talavera, 2015, p. 208-209). Pues, la literatura aumenta la "capacidad de imaginación moral” sensibilizándonos en la comprensión del otro. Aunque también es verdad que a este "ironista" por excelencia le falta la fe que permite conectar con la virtud, la empatía y las posibilidades de aprendizaje. Y más bien indaga en la crueldad y el daño para comprender al otro. Si bien, en realidad, esto no es más que seguir otro camino para llegar a un punto cercano a la moralizante empatía de Nussbaum.

Ahora bien, llegados a este punto en el que parece claro que la literatura sería capaz de sostener visiones edificantes y moralizantes que favorecen la virtud de la actuación jurídica en los distintos niveles legislativo y judicial, podemos legítimamente cuestionarnos ¿por qué leer novelas desarrolla capacidades que permiten realizar mejor las exigencias morales normativas?

Se dirá que porque la virtud se aprende. Y es precisamente la literatura la que la enseña. Porque "nos separa de una visión del Derecho formal, de la elaboración mecanizada de normas, y nos lleva en sentido contrario hacia todas las posibilidades, probabilidades y ambigüedades que la vida posee" (Hayman; Levit; Delgado, 2002, p. 463). Así nos dota de una "instancia ética que nos invita a relacionarnos con el bien de otras personas que tienen una vida distinta de la nuestra" (Nussbaum, 1995, p. xvi), fomentar la empatía que nos sitúa en la posición del otro y nos hace comprenderlo y preocuparnos por él y, así, abrirnos las perspectivas que deconstruyen los estereotipos que alimentan los odios colectivos (Silva,

18 En similar sentido, François Ost (2006) insiste en los frutos importantes que se pueden recoger de la constructiva dialéctica que impulsa la "ficción" y la "irracionalidad", el "todo vale" de la literatura frente al "tener que" del Derecho. 
2006, p. 161; Duarte, Maders, 2016, p. 165) y los prejuicios y fobias, intereses, errores e ignorancias ${ }^{19}$ que predeterminan las decisiones en la narración jurídica (García Amado, 2003, p. 361 et seq.).

Desde luego yo estoy convencida, y creo que cualquiera, de que cuanto más justo sea el Derecho, cuanto más se preocupe por todos y les responda satisfactoriamente, mejor.

Pero, ¿empatizar, imaginar, contextualizar... es condición suficiente y/o necesaria, para conocer el Derecho y hacer justicia? Y, ¿̇cuáles son los límites de la empatía que nos permiten ser imaginativos y simpáticos sin caer en el relativismo de lo que unos consideran lo moral y virtuoso frente a quienes sostienen justamente lo contrario?

Al fin y al cabo, el Derecho siempre es bilateral; si comprendemos a uno, pierde el otro; y si es el otro el que consigue nuestra simpatía imaginativa volviéndonos empáticos a sus necesidades, intereses y virtud, entonces pierde el primero.

Pues bien, y aunque me parece muy recomendable la apertura emocional y crítica que permite la literatura, creo que, en sentido estricto ni es condición necesaria ni tampoco suficiente de la justicia del Derecho y de la resolución. E incluso, en ocasiones, cuando se radicaliza su importancia en detrimento de las condiciones técnicas del Derecho, puede representar un problema serio para la igualdad, la imparcialidad, la deducibilidad y la seguridad jurídica, los derechos, etc. si, bajo excusa de radical ajusticiamiento literario, se construye un modelo tan denso de virtud para el Derecho y el juez que olvidamos la justicia de la legalidad, las formas y los procedimientos prestablecidos. Llegados a tal punto bastará creer que lo que diferencia a un caso fácil de uno difícil no lo determina la lectura de las reglas jurídicas, sino la habilidad y particular sabiduría moral del juez para convertir ciertas consideraciones fácticas, valorativas e ideológicas en elementos de juicio y racionalidad jurídica capaces de derrotar la aplicación fácil de la norma en favor de la "inesperada" virtud de un caso ya reconstruido como difícil (Amaya, 2013).

19 Pues las ficciones literarias "proporcionan detalles sobre formas de sufrimiento de personas en las que no habíamos reparado.... Y también ofrecen detalles sobre las formas de crueldad de las que somos capaces y... nos permite redescribirnos a nosotros mismos" (Rorty, 1991, p. 18). 
Luego retomaré este problema. Me limito ahora a dejar apuntada la necesidad de relativizar la importancia valorativa de la justicia literaria en relación con los valores de seguridad jurídica y libertad que favorece el Derecho, al menos, de los Estados democráticos desarrollados, por más que resulte fundamental la labor material deconstructiva de prejuicios, intereses partisanos e ideologías conservadoras que el Derecho positivo acostumbra a trasladar. La labor ponderativa, pues, pero justificada y técnicamente ajustada resulta aquí fundamental.

\subsection{El derecho como literatura}

Esta categoría interesa especialmente, porque entiende que el Derecho - el objeto a conocer- es literatura. Y de esta forma no solo se transforma el objeto - el Derecho ahora es literatura, no un cuerpo objetivo, científico y riguroso -, también se alteran los paradigmas racionales del conocer y su correspondiente metodología. De tal forma que el texto literario del Derecho puede someterse a las reglas de producción, lectura, comprensión, crítica e interpretación de la literatura. El objeto neutral, aséptico y formalizado se hace poesía y el método científico se refunda como imaginación. El jurista investigador, teórico y científico se desviste la bata blanca para enfundarse en el jersey de lana y las zapatillas del narrador que frente a la chimenea da vida y voz a sus personajes reconduciéndoles al mejor fin de la historia.

Un planteamiento literario que actualmente se ve muy favorecido por una realidad jurídica y política que está desmontando en la práctica las confianzas del positivismo decimonónico en la ciencia jurídica, la codificación y el legislador omniscente. Porque hoy el legislador desaparece materialmente tras el gobierno, el electoralismo, los poderes fácticos, los intereses y la corrupción, etc. Por su parte, el juez parece convertirse en el nuevo y único héroe capaz de hacer justicia frente a las tropelías e insensibilidades. Y el ciudadano se adscribe a grupos de interés y de indignación que enarbolan el "nada vale"...

En este contexto de adecuadas insatisfacciones, entender el Derecho como literatura sirve, a unos, para aplicar los instrumentos de crítica literaria a los textos jurídicos como criterios de interpretación, adquiriendo especial relevancia la retórica y las nuevas perspectivas hermenéuticas 
literarias (Pêpe, 2016, p. 8-10). Y a otros, para exaltar el poder persuasivo y justificativo de convertir al Derecho en una narración activa y dinámica que sirve a las voces marginadas y al proceso judicial como una equilibrada contraposición de narrativas entre personajes.

Veamos esto más sistemática y detenidamente.

\subsubsection{Primer campo de desarrollo del derecho como literatura, el campo interpretativo (legal texts as literary texts)}

Lo que ahora se está proponiendo es emplear los recursos y categorías de la interpretación y crítica literaria para desarrollar una metodología jurídica de la interpretación en cuanto conjunto de técnicas y procedimientos jurídicos destinados a encauzar el proceso de identificación, determinación y calificación jurídica de los hechos y decisión del caso.

Y para ello se estarían dando por presupuestas dos cosas importantes. Una, que el texto jurídico no incorpora la definición de su significado verdadero respecto del caso concreto, por lo que queda en manos del juez la interpretación de la significación y solución que deba ser respecto del caso. $\mathrm{Y}$, otra, que - hermenéutica de línea gadameriana ${ }^{20}$ y racionalidad práctica alexyana - existe "unidad interpretativa" entre los diversos tipos de texto. Esto es, la hermenéutica jurídica no difiere de la de cualquier contexto y, en consecuencia, se le pueden aplicar con éxito los criterios interpretativos literarios ${ }^{21}$.

A partir de aquí, se animan soluciones postmodernas de interpretación que se centran en la justicia del caso y no en el universalismo y la imparcialidad, y que impugnan el silogismo de la aplicación y su idea de que existen unos hechos objetivos que se pueden "subsumir", introducir, en la ley para generar, producir, de forma automática un resultado.

De esta forma se fortalecen los "iuspositivismo blandos" que pretenden, cada uno con su arsenal argumentativo, un post-positivismo que

20 Atiendo aquí a Verdad y método y a Estética y hermenéutica.

21 En términos de Aarnio, la interpretación jurídica y la literaria son "esencialmente «dependientes del lector»... La teoría de Ingarden... es bastante típica al afirmar que la interpretación de una novela necesita no salir "fuera del lector»" (Aarnio, 1987, p. 113). Para él, el Derecho puede ayudar a depurar los criterios interpretativos literarios conforme a los criterios de autoridad y auditorio universal (Aarnio, 1987, p. 115 et seq.). Y, a su vez, la teoría literaria puede colaborar con el Derecho especialmente en el "análisis del proceso de interacción" (autor, intérprete, auditorio). 
incorpore la emoción, la sensibilidad, la empatía, la justicia en la decisión judicial pero, al menos eso pretenden, y en la misma línea p.ej., Nussbaum, sin saltarse las condiciones y límites de la ley $^{22}$. Formulaciones que, desde luego son intensamente contestadas desde el normativismo duro, formal, excluyente, neutral e imparcial.

Pero detengámonos un poco en esta propuesta post-moderna y postpositivista, o de iuspositivismo blando, por cuanto pueda beneficiarse de la aportación literaria.

$\mathrm{Al}$ respecto, partiré de las tres alternativas interpretativas literarias fundamentales de la época moderna, y que, grosso modo, coinciden con las tres variantes interpretativas del Derecho ${ }^{23}$. Una, restrictiva, es la que se centra en la interpretación subjetiva o intencional del autor (Romanticismo literario). Otra es la que asume la interpretación objetiva de la verdad significativa del texto y, a su vez, adopta distintas formas y grados, desde el literalismo interpretativo y declarativo hasta un new criticism que busca la interpretación verdadera de la narración y del que Dworkin es buen ejemplo de aplicación al Derecho. Y, finalmente, la tercera alternativa, extensiva, se centra en la interpretación y recreación por el intérprete-lector (reader response school). Es la revuelta de la "estética de la recepción" y que desde la primera década de este siglo reclama el antifundacionalismo del criticismo literario, p.ej., Fish.

22 En este mismo sentido, y en la línea de Nussbaum, Duarte y Maders, reclaman una interacción conjugada entre Derecho y literatura conforme a la que, para el juez, "el límite creativo es el conocimiento de la ley, los precedentes jurisprudenciales y de la complejidad de los problemas sometidos a enjuiciamiento" (Duarte; Maders, 2016, p. 174)

23 Inicialmente, interpretar la obra consistía en "descubrir" la intención del autor. Luego la obra se independizó del autor adquiriendo sentido como totalidad, es el tiempo del estructuralismo. Y, finalmente, se produce la "rebelión el lector", con la que la obra se abre a muy distintos sentidos que dependen de la mirada de quien lee (Eagleton, 1983; 1985). La comprensión paralela del Derecho como texto convierte en asunto fundamental "si los textos tienen un significado determinado objetivo e identificable; si el significado de un texto podría coincidir con la intención del autor; y si los lectores, en el proceso de interpretación, son libres para asignar la significación al texto" (Hayman; Levit; Delgado, 2002, p. 463). Comp. Aguiar e Silva (2001, p. 80-81). Cárcova lo señala enfáticamente refiriéndose a las tres etapas de la interpretación literaria: autor, estructura y lector intérprete, "¿ं(n)o es posible encontrar en estos momentos de evolución de la crítica literaria, una franca correspondencia con el predominio de la exégesis, el método sistemático o de la interpretación creativa de los jueces...?” (2000, p. 3). 
Pues bien, las cuestiones relevantes aquí son: cuál es el método o teoría literaria victoriosa ${ }^{24}$. Si las concepciones críticas de la interpretación literaria se pueden proyectar como criterios de interpretación jurídica. Y, en caso afirmativo, cómo ha de hacerse.

Podríamos partir de que el método a aplicar al Derecho es el que haya vencido en lo literario. $\mathrm{Y}$, en este sentido, es frecuente escuchar que la interpretación de la voluntad del autor pierde frente a la centrada en la emoción e intención del lector. Barthes ya anunció la "muerte del autor", en 1968, que completaba la nietzscheana "muerte de Dios". El texto se recrea y reinterpreta una y mil veces a través de la interpretación. Aunque entonces lo que se objeta desde distintos frentes ${ }^{25}$ es un infructuoso psicologicismo que, si se proyecta sobre el Derecho, es muy conflictivo al atentar contra los límites objetivos del texto.

Por todo ello el new críticism, frente al originalismo y el psicológicismo interpretacionista, apuesta por la interpretación del lector, pero trascendiéndola con la hermenéutica de la tópica, los prejuicios y mundos de vida (Gadamer, segundo Wittgenstein,...). Esto permite una fusión significativa de horizontes en un intérprete real que inyecta interpretación verdadera al texto ${ }^{26}$.

$\mathrm{Y}$ al integrar hermenéuticamente al autor en un contexto referencial de significado verdadero para el crítico, el New Criticism incorpora la tesis de que los documentos literarios que pasan a la historia suelen estar realizados por autores geniales. Lo que nos remite a la "tesis de la total coherencia” (Olsen, 1978, p. 137-155): ningún detalle de la obra es un

24 Remito aquí a la muy interesante revisión del criticismo literario del Derecho que ofrecen Guyora Binder y Robert Weisberg (2000, p. 112 et seq.).

25 Paradigmáticamente, Ian Ward (1995), en "Text, author and literature in legal studies", reclama nuevamente, empleando la categoría foucaltiana de "función-autor" - el autor mismo es el resultado de un proceso complejo de vinculaciones institucionales, sociales, culturales que constituyen un determinado "ser de razón" -, volver a introducir la figura del autor en la interpretación de los textos. Ilustrativa al respecto la conferencia de Foucault sobre la consistencia del autor, las cuestiones que se le formulan y sus correspondientes respuestas, en https://azofra.files.wordpress.com/2012/11/que-es-unautor-michel-foucault.pdf

26 Dicho de otro modo, se trata de defender "el New Criticism contra el intencionalismo, pero no argumentando que el contexto histórico sea irrelevante para la interpretación, sino sosteniendo que el intencionalismo «excluyó el adecuado diálogo entre el pasado y el presente y postuló un concepto de historia divorciado de los intereses y asuntos presentes»... la tendencia de Gadamer de antropomorfizar el texto es una alternativa útil frente a la escolástica proliferación de entidades mentales requeridas por la fenomenología" (Binder; Weisberg, 2000, p. 133). 
accidente, todo contribuye a su significado e impacto emocional y a la grandeza de la literatura y cuánto nos enseña.

Sin embargo, también la adecuación y pertinencia de este New Criticism literario soporta importantes embates; en concreto, por su posible inadecuada metodología, porque su presupuesto subjetivo objetivado sería dudoso ${ }^{27}$, y por su posible carácter reaccionario (Binder; Weisberg, 2000, p. 145).

Ahora voy a intentar trasladar esto al campo jurídico.

Como apuntaba, las tres vías de interpretación literaria señaladas subjetiva del autor, objetiva del lector, subjetiva del intérprete - tienen su reflejo en las tres categorías básicas de la interpretación jurídica. La subjetiva y voluntarista, que impulsa el originalismo, la objetivista y la interpretativista. Caracterizándose las tres por un importante desarrollo en el campo del Derecho y un fuerte planteamiento crítico que hace aumentar el interés acerca de qué aportar o puede aportar la teoría literaria a la interpretación jurídica.

Y aquí me interesa especialmente el New Criticism por la influencia jurídica que ha conseguido demostrar para el postpositivismo y de la que es paradigmática la tesis jurídica de la novela en cadena que propone Ronald Dworkin quien, a su vez, para bien o para mal, ha tenido una repercusión conmovedora en los marcos de interpretación y conceptualización del Derecho.

El punto de partida de Dworkin era su crítica al iuspositivismo formalista, que reducía injustificadamente el Derecho al texto de las reglas descriptivas.

Como es sabido, la "hipótesis estética" de Dworkin busca en la literatura un recurso iluminador para la interpretación jurídica ${ }^{28}$. El diseño es la "novela en cadena", integrada por capítulos narrados por escritores diferentes, cada uno de los cuales escribe un nuevo capítulo - se sortea al comienzo qué capítulo le toca escribir a cada novelista - que es

\footnotetext{
27 "El New Criticism y el deconstruccionismo son un continuo, y ambos se oponen a lo que considero la actitud correcta frente a la interpretación de las leyes y los textos constitucionales" (Posner, 1988, p. 240).

$28 \mathrm{Y}$ es que, "podemos mejorar nuestra comprensión del derecho si se compara la interpretación jurídica con la interpretación en otros campos del conocimiento, en particular en la literatura" (Dworkin, 1983, p. 143).
} 
continuación del anterior una vez ya se ha desprendido de su autor. El objetivo es encontrar la mejor interpretación para la cadena de capítulos que integran la novela. Planteamiento éste que desarrolla respecto de casos conflictivos imaginarios o reales, como el aborto en Roe vs. Wade, y que encaja bien en las propuestas literarias de los New Critcs y el "lector implicado" (Iser, 1974, p. 282).

A partir de aquí, se aplica analógicamente el planteamiento a la sentencia judicial, y se integra al jurista como un autor de la novela en cadena en que consistiría el Derecho. Así, el juez de un caso difícil - la regla positiva no tiene una aplicación autoevidente al caso- debe actuar como un narrador que tiene a su cargo la redacción del capítulo final de una cadena de capítulos previos escritos por otros juristas y jueces. Y aunque todos contribuyen a la obra total, la libertad creativa de cada juez como intérprete está acotada por el entretejido lógico-argumentativo que lo precede y, en cierto sentido, por el que le sucederá ${ }^{29}$. De esta forma, la reconstrucción interpretativa del espíritu del relato jurídico se integra hermenéuticamente, inyectando al texto el mejor sentido y significado posible pero respetando su integridad sustancial como relato.

Conforme a este planteamiento, Dworkin no es intencionalista ni en lo jurídico ni en lo literario (Posner, 1988, p. 178). Pues la interpretación se desvincula del autor y busca la única respuesta correcta - el capítulo final integrado en una novela de sucesivos capítulos escritos por distintos autores. Por eso la propuesta es trabajar interpretaciones más estructurales u holísticas que alumbran la verdad del texto, su interpretación verdadera, la única interpretación correcta.

Como señalaba, la repercusión de la propuesta de Dworkin de la "única respuesta correcta" ha sido extraordinaria en el ámbito jurídico, y por ello también grande ha sido el impacto de la propuesta de la "novela en cadena" como esfuerzo de transposición de lo literario al ámbito jurídico. Pero, desde luego esto no la ha librado de muchos problemas. Apunto ahora solo los que le afectan por el lado literario, porque para el jurídico nos falta aquí mucho espacio.

29 Planteamiento éste en el que, a su vez, late la ya apuntada idea base del New Criticism de que los autores de la Constitución, de los derechos y de las leyes más representativas "son en su mayor parte profesionales altamente competentes" (Posner, 1988, p. 247) capaces de fijar la interpretación correcta del texto jurídico. 
Para Dworkin, igual que el intérprete-crítico literario debe descubrir las claves que mejor revelen al texto como una verdadera obra de arte, el jurista debe conseguir una obra jurídica maestra, ila única solución correcta! El problema es que, como él reconoce, no hay fórmulas algorítmicas de desarrollo correcto de cada capítulo y del final. En la novela la interpretación mejor de los precedentes puede guiarse por la estética. El problema es que la interpretación jurídica en términos de integridad no aspira a la estética, sino a interpretar adecuadamente las condiciones morales y políticas que ofrezcan los principios y reglas constitucionales y, al menos en las sociedades desarrolladas, a la protección de los derechos individuales.

Responderá Dworkin, que igual que la hermenéutica literaria, sin ser tarea unívoca y posibilitando distintas interpretaciones, tiene límites, pues no se puede adulterar la obra original - podemos dudar si Hamlet es un esquizofrénico o un edípico, pero no podemos interpretarlo como un personaje ligero o banal -, de la misma forma el juez o el jurista que interpreta, también tiene la limitación de no adulterar el material que analiza: declaraciones de testigos, confesiones de las partes, alegatos de los abogados, normas aplicables, dictámenes periciales, etc. pero más allá de esto, debe valorar materialmente la respuesta correcta en términos de principios. Lo que puede obligar al juez a apartarse o contradecir la regla positiva del Derecho.

$\mathrm{Y}$ se fortalecen los problemas: Porque puede tener o no sentido apartarse de la voluntad del autor en la obra literaria. Pero los legisladores, en democracia, a diferencia de los escritores de literatura, representan a los destinatarios del texto de la ley. Porque no se dan razones para creer que existe un sentido trascendental en los contenidos de la cadena normativa jurídica que avale una interpretación verdadera ${ }^{30}$. Y porque, además, la tesis de la única respuesta jurídica correcta incorpora la arriesgada afirmación de que la interpretación genera una respuesta correcta y racional en los casos jurídicos difíciles, lo que recomienda convertir cada caso en difícil, desatender siempre la regla positiva en favor de la solución racional y verdadera.

30 Tampoco se darían para la novela; de hecho, para muchos críticos literarios el New Criticism de la interpretación textual verdadera está ya fuera de juego. Igual que para un sector extenso de la doctrina académica y jurisprudencial la "única verdad" de la tesis de la única correcta es que es "falsa". 


\subsubsection{Segundo campo, campo de la retórica (law and literature as language)}

La retórica es uno de los instrumentos de conocimiento y convicción básicos del planteamiento postmoderno en general y, en particular, un eje reivindicativo central de la comprensión del Derecho como literatura.

Es verdad que frecuentemente la retórica es acusada de persuasión innoble y orientada a la convicción en la falsedad, una forma de manipular al juez. Ya los sofistas y Sócrates, Platón y Aristóteles la objetaban por entender que, con demasiada frecuencia, se empleaba ante grandes auditorios para manipular y persuadir las emociones omitiendo hechos y razones. Por eso Perelman diferencia el auditorio universal del particular.

La exaltación del método retórico y hermenéutico para el conocimiento y construcción del Derecho, en el ámbito europeo, se impulsan con los paradigmáticos trabajos de Perelman - y su retórica pragmática - y de Gadamer - y su hermenéutica-cultural.

En términos básicos, la retórica jurídica reclama observar, valorar y superar los argumentos técnico-jurídicos y lógicos para indagar y descubrir los valores sociales realmente operativos y persuasivos a fin de exponerlos y convencer de su mayor justicia.

El precursor inicial de la retórica literaria para la identificación y concreción del Derecho es Boyd White. Para él, el Derecho no debe entenderse como un sistema de reglas, sino como una disciplina retórica que ofrece las técnicas para afirmar y transformar nuestras prácticas sociales (Pereda, 1998, p. 103-5, 112-113, 117, 123-124) al generar un uso persuasivo del lenguaje que anima la integración social de quienes participan en la producción cultural y los valores de la comunidad.

La retórica jurídica del Derecho como literatura entiende que el análisis del Derecho no admite formalización ni objetivización - así, se habla, p.ej, de la función retórica de la Constitución, que nos persuade de la bondad y moralidad de un determinado modelo comunitario de vida y justicia. Solo la capacidad de persuasión ofrece un criterio de corrección de los asuntos prácticos de los que se ocupa el Derecho. Por eso, debemos contemplar "el argumento legal como un ejemplo de retórica" (Frug, 1988, p. 871). Al fin y al cabo, la función persuasiva del lenguaje es un elemento común al Derecho y la literatura que trata de orientar el discurso, más allá de la persuasión, al convencimiento respecto de lo que se intenta transmitir. 
Función retórica bien presente p.ej., en el contexto de la argumentación comunitarista (Talavera, 2006, p. 44) y en los conceptos de "comunidad narrativa", "relato fundante" (Castoriadis, 1975, p. 457), "comunidad cultural”, "tradición de pensamiento" (Ward, 1999, p. 166 et seq.), etc.

\subsubsection{Tercer campo de desarrollo del conocimiento del derecho: la narrativa}

Se apela ahora a la naturaleza esencial del Derecho como narrador de historias. Las historias mejor narradas y más convincentes se convierten en argumentos y soluciones jurídicas (Legal storytelling movement). Lo que sirve para deslindar, al menos, cuatro líneas narrativas.

Una, destaca la importancia de la narrativa en las argumentaciones y fundamentaciones judiciales, pues el caso jurídico es un conjunto de relatos narrados por un tribunal. Así, el Derecho procesal debe centrarse en cómo narrar las historias y las distintas disciplinas del Derecho en contar historias que nos gusten; sobre personas que contratan, que engañan o hacen daño, etc. Se trata aquí de destacar la visión del proceso como una competición entre las narrativas sustentadas por las partes ${ }^{31}$. El proceso se inicia con el relato del autor que trata de detallar pormenorizadamente un hecho en el que pueden haber intervenido más personas y que produce efectos que afectan a la realidad, y que son atendidos por el Derecho. Luego continua con el relato de la otra parte que presenta otra historia en relación con los mismos hechos y condiciones pero buscando conclusiones alternativas. Y luego aún llega una tercera versión de la historia, que es la del juez o tribunal. Pudiendo darse más versiones si hay votos disidentes o respuestas diferentes de los tribunales vía recursos (Talavera, 2006, p. 50-51).

Igualmente, segunda línea, la literatura se convierte en un aspecto central para la concreción y determinación de la prueba - hechos, tiempos, sentimientos,...- como se pone de manifiesto en Coherence in legal justification en Rhetoric and The Rule of Law, de MacCormick (1984; 2005).

Tercera, la literatura narrativa ofrece el elemento decisional que sustituye al proceso silogístico. La decisión judicial deja de ser el resultado

31 Atiéndase, p.ej., a "The Law as legal rhetoric", de Brooks (1996); "Seduced by narrative: persuasion in the courtroom", de Kadoch (2000); "Courtroom narrative and finding of facts", de Stratton (2004); o "Narrative theory and the Law", de Conti (2000). 
de una lógica deductiva y formal entre premisas verdaderas y se configura como lo que realmente es, un proceso real de ajuste de la historia más plausible de los hechos narrados a la historia descrita por la norma aplicable ${ }^{32}$.

Y, para la cuarta línea es muy importante la capacidad de la narrativa para dar voz a las personas y grupos vulnerables ajenos a la producción jurídica. Y es que, la narración de historias - storytelling - sirve para reimaginar el Derecho narrando historias y experiencias personales, parábolas, visiones imaginativas, anécdotas que inspiran la empatía y el reconocimiento de los intereses compartidos para integrarlas en libros y artículos sobre el Derecho. Importa aquí especialmente la perspectiva crítica que permite ver que muchas de las historias del Derecho silencian a determinados actores de grupos desfavorecidos o los colocan en posiciones de desventaja o maldad predeterminadas y poco convincentes $\mathrm{e}$ insatisfactorias para el lector. Esas narraciones - tan empleadas por la outsider jurisprudence, la critical race theory, la gay legal narrative,... tienen el efecto contrahegemónico de subvertir las historias oficiales que se encuentran en la base de las doctrinas tradicionales característicamente opresivas y privativas 33 .

\section{CONCLUSIONES}

Estoy convencida de que la concepción literaria puede ayudar en el análisis, difusión y mejora del Derecho gracias a sus funciones pedagógica, edificante y gnoseológica. Pero también creo que no hay que perder de vista sus carencias, en parte derivadas de que la literatura refiere textos no normalizados y descontextualizados de los ámbitos científicos (social, formal o técnico) de conocimiento. Sintetizo ahora esas problemáticas carencias y las virtudes con que la concepción jurídica literaria puede afrontarlas, como herramienta de balance.

Primero, en relación con la justificación del modelo de justicia.

32 Cfr. symposium sobre "Legal storytelling" de la Michigan Law Review; tmb. symposium "Law and literature: examining the limited legal canon", de la Rutgers Law School; y el Law Stories de Below y Minow (1998).

33 "A través de las historias, los actores legales se ven individualizamente y en un contexto humano... se evidencia la «voz humana» frente a las estériles palabras de las doctrinas y las reglas" (Hayman; Levit; Delgado, 2002, p. 464). 
El eje central de la empresa del Derecho en la literatura es la búsqueda de valores de justicia. Lo articula paradigmáticamente Nussbaum en su Poetic Justice recorriendo textos y autores para extraer representaciones valiosas de formas de empatía y solidaridad que le sirven para elaborar un concepto de justicia más complejo, auténtico y necesario que el que se puede formular desde el aislamiento de la razón individual universal moderna. Porque la libertad constructiva y crítica de la literatura es garantía de problematización, de subversión, de búsqueda, de denuncia, etc. Y no me cabe duda de que si desapareciera, la justicia sería otra.

Pero también veo dificultades en la justicia literaria del Derecho. Pues el problema de la justicia no es que no tenga textos, contenidos y contextos sino, precisamente, que tiene demasiados y contradictorios, que su contenido es complejo y controvertido, y que se precisa un instrumento que sirva para seleccionarlos y priorizarlos de una forma justificada (Seaton, 1999, p. 489-490). De hecho, desde los más diversos ámbitos del conocer, también el iusfilosófico, se ha empleado mucho tiempo y energía en esa búsqueda. Pues tan habitual como que cada cual tenga su concepción de lo justo es que cada una de esas concepciones choque con las de los demás.

En este sentido, realmente creo que tanto Nussbaum como otros muchos aciertan en su afán de definir la justicia del Derecho buscando en la literatura al otro, la diversidad, lo contingente, la racionalidad múltiple y la deconstrucción como forma de liberación de las jerarquías y binomios ortodoxos de prevalencia y dominio.

Pero también creo que aciertan porque ya parten de que la liberación y el reconocimiento del otro diferente son justos. Y esto les da la ventaja de poseer un criterio que justifica la selección de los textos adecuados. De tal forma que la literatura seleccionada es una demostración o ejemplificación de aquello que precisa lo justo frente y contra la literatura que no acuerda en tal planteamiento. Pero no una justificación de lo que lo convierte en justo.

Y hete aquí que, entonces, si no hay más justificación de esa selección de textos edificantes de la justicia y los valores del Derecho que el "prejuicio", de Nussbaum y los demás, y que yo por cierto comparto, acerca de lo justo, entonces los textos literarios ni construyen, ni ayudan a buscar, solo sirven de ejemplo o puesta en juego de lo que previamente ya nos 
parecía justo respecto de supuestos que narran literariamente soluciones que desde antes de la lectura literaria creíamos correctas. Realmente, no se trata de una objeción nueva, ya la hacía Posner, para quien, de ser cierto que la literatura aboca la bondad moral, no habría por qué seleccionar los autores y textos de aspiración liberal que nos gustan. Podríamos elegir otros autores, otros modelos literarios, otras creencias... Algo en lo que insiste Díez; “(n)o existe en el libro de Nussbaum un solo argumento para convencernos de que es preferible leer a Dickens o a Wright que a Céline o a Pound, por destacar a dos escritores malvados" (Díez Gargari, 2008, p. 153).

La segunda dificultad se refiere al antiformalismo de la concepción literaria y los problemas que destila respecto de la dinámica jurídica.

Por una parte, en particular, respecto de los sistemas de Derecho legicéntricos y sus diferencias con los de Common Law, porque un análisis literario del Derecho parece en principio, más comprensible y provechoso en un contexto acusatorio fortalecido por el jurado y la emotividad, como el estadounidense, en el que ha tenido una impronta muy importante. Y más problemático en modelos jurídicos legicéntricos y culturalmente diferenciados en los que podría animar, dirán algunos, la discrecionalidad irrestricta y justiciera de los jueces.

Ahora bien, y frente a esta comprensible objeción, también hay que reconocer que por mucho que nos empeñemos desde el marco legicéntrico en la formalización, la conceptualización y la ley, el Derecho tiene en ambos contextos la misma naturaleza narrativa y de identificación, concreción y comprensión de los hechos. Por lo que la literatura mantiene la misma pertinencia en la calificación jurídica de los hechos al aportar elementos empáticos, de sensibilización y crítica $^{34}$ y en la deconstrucción de la valoración de los mismos.

Por otra parte, la propuesta literaria choca con la acusación de "blandura" conceptual. Pues no habría una teorización referente sobre la relación entre el Derecho - normativo - y la literatura - emotiva - ni sobre sus instrumentos conjuntos (Carreras, 1996, p. 36). Si la hubiera, dirá el

34 Se apunta tmb. a esta idea en Freitas (2002, p. 20). 
crítico, se podría valorar si muchos de sus parecidos no serían solo coyunturales 35 .

$\mathrm{Y}$ en este contexto se destaca que aunque la concepción literaria, su apertura y criticismo frente el dogmatismo son muy atractivos, quedan pendientes cuestiones relevantes - criterios valorativos e interpretativos, justificación de la retórica, posición y método del intérprete, etc.- que exigen justificaciones que dependen de asunciones dogmáticas y construcciones teóricas ${ }^{36}$ de las que la literatura presume de carecer. Objeción que vuelve a dar forma a la que Stanley Fish lanzara a los CLS acusándoles de la "anti-foundationalist theory hope"37. Pues, cuando se quiere demoler las bases tradicionales de todas las disciplinas demostrando que la verdad y la justicia son solo interpretaciones o creaciones de una concreta corriente ideológica, la propuesta, en este caso la de la justicia literaria, sufre un suicidio dialéctico, pues no aplica el mismo rasero crítico a sus postulados y defiende su justiciera verdad dogmáticamente (Fish, 1987b, p. 1796).

La tercera dificultad habla de las deficiencias de la literatura como recurso formativo en la virtud del Derecho. Pues, ¿qué lleva a los defensores de la visión edificante del Derecho en la literatura a creer que la virtud, la bondad, la ética y la empatía se adquieren leyendo textos literarios? ¿Qué se aprende, qué se debe aprender, cómo se aprende, de quién y por qué?

Aquí la objeción se despliega en racimo generando diversos conflictos y cuestiones.

Porque, para adquirir la virtud el lector debe haber preseleccionado "bien" previamente los textos, deben ser textos de liberación, que inviertan la jerarquía de dominación y la voluntad de saber y poder de la raza, el capital, el patriarcado, la heterosexualidad, la religión, etc.

35 Se apela aquí a las diferencias entre los "mercados" del texto legal y literario: uno es poco competitivo, referido al juez y los involucrados en el caso, el otro de potencial público universal y atento a la originalidad, la transgresión, la emoción,... Además, el Derecho es normativo y traumático, el texto legal se somete a la legalidad y la uniformidad doctrinal $\mathrm{y}$ jurisprudencial rigiendo criterios interpretativos auténticos y normativamente delimitados, mientras que en la literatura no, porque es emoción e imaginación no condicionada. Tmb. comp. Posner (1988, p. 249 et seq.).

36 Se insiste en esta cuestión crítica en García Valverde (2009, p. 63 et seq.; 76). Tmb. Botero-Bernal (2008, p. 80).

37 Tmb. Posner (1988, p. 217) destaca cuanto de históricamente contingente, subjetivo e inverificable hay en las pretensiones postestructuralistas y en la afirmación de que todo planteamiento objetivo es imposible. 
A esto debe añadirse que ninguna prueba hay de que la literatura posea una fuerza normativa innata al texto que nos haga mejores personas y con mejor capacidad de juicio ${ }^{38}$.

Podrá responderse que lo que se sostiene no es que la literatura sea condición suficiente de la formación, sino que es una condición solo necesaria, no suficiente. Además de ser una persona culta que realiza las lecturas adecuadas, el jurista poseer una buena formación técnica.

Pero también esto es problemático (Botero-Bernal, 2008, p. 55 et seq.). Porque aun tratándose de la literatura apropiada, el aprendizaje en la virtud depende de diversos factores y procesos mentales, poéticos, estéticos, emocionales, contextuales, etc. Lo que se demuestra cuando la persona es mala, incluso aberrantemente dañina y destructiva, pero tiene mucha cultura $^{39}$ literaria, incluso puede ser un gran autor ${ }^{40}$. P.ej., Thomas Mann era pronazi y muchos los altos cargos de Hitler, como muchos dictadores y tiranos, eran personas cultas y versadas en la literatura de Goethe, Shiller, Kant,...

$\mathrm{Y}$, en este mismo sentido pero ahora en dirección contraria, tampoco se ha probado que la persona que no lea literatura, el "inculto literario", carezca de bondad y conocimiento ético.

En efecto. Para mal y para bien, la realidad ya se ha encargado de demostrar que ambas afirmaciones son falsas. No ser culto y "leído" no aboca al ser humano a la maldad o la molicie ${ }^{41}$. Y serlo no es una garantía de justicia y razón. La literatura, como tal, no pueda hacer a los seres humanos mejores (Díez Gargari, 2008, p. 164-165), ni puede enmendar la plana del

38 Seguramente la literatura puede ofrecernos una visión y sistematización más amplia del otro, sus necesidades, problemas y puntos de vista que la que traslada la vida real. Pero, aun así, "no hay razón para suponer que una más amplia comprensión de la naturaleza humana nos transforme en mejores personas" (Posner, 1988, p. 315-316).

39 Como demostración en términos analíticos de la falta de justificación de la cultura, en concreto la jurídica (Suárez Llanos, 2004, p. 15 et seq.). Y en clave literaria, p.ej., Woody Allen, “¿Cómo acabar de una vez por todas con la cultura?”, en su recopilación de Getting Even.

40 Lo destaca también Roberto Saviano. La creencia social de que los malos no leen es falsa. El chapo Guzmán lee; cuando lo detienen tiene en su cama CeroCeroCero. Y Gomorra, su primer libro, sobre economía y poder era muy leído en las cárceles del sur de Italia. “...El perfil de los jefes de las principales organizaciones criminales se asemeja mucho... al de los consejeros delegados de cualquier respetada empresa internacional". Cf en: http://internacional.elpais.com/internacional/2016/02/21/actualidad/1456077917 728 864.html.

41 Con cierta vehemencia Botero-Bernal (2008 p. 79 et seq.). 
jurista que carece de habilidades técnicas e instrumentales que requieren las disciplinas jurídicas (Posner, 1998, p. 318).

Ahora bien, reconocido esto, también reconozco que me sirvo de una cierta retórica estratégica en las afirmaciones previas, en las que late mucho del argumento de "si al menos puede darse un caso en el que..." (malvado culto literario-bondadoso inculto literario). Porque aunque se dan muchos casos en los que ni la lectura formó buenos juristas ni su falta los deformó, generalmente, la incursión en la realidad de la conducta, necesidad, interés, valoración,... de las personas y los grupos invisibles para la política y el Derecho actuales nos permitirá o facilitará comprenderlas y enfrentarnos a los prejuicios valorativos infundamentados que están detrás de cada norma y cada interpretación y aplicación normativa.

La cuarta dificultad se refiere a las posibles fricciones de la empatía y la simpatía con la autonomía racional y crítica.

$\mathrm{Y}$ es que, cuando la estrategia literaria para alcanzar la virtud de la justicia es empatizar e identificarnos con los personajes, ponernos en su lugar, reducir la otredad a un nosotros, la pregunta es ćquién es el otro? ¿Yo, ellos, nosotros o alguien a quien no conozco?

Ya se ha visto que hay varias posibilidades. Abandonar el yo en favor del nosotros que objetive el sentido hermenéutico. Lo que genera el problema de que perdemos la perspectiva crítica imprescindible para establecer un concepto valioso de lo justo. También puede mirarse al lector concreto ${ }^{42}$. O a la interpretación impersonal, distante y atenta a la estructura interna de la obra. Pero al involucrarse el jurista con los personajes o volverse él mismo autor contradice las premisas y valores de universalidad, generalidad, neutralidad e imparcialidad, atizándose la polémica del intérprete virtuoso pero irrespetuoso de la seguridad jurídica de Derecho positivo.

Dicho de otro modo. La empatía y simpatía con los personajes puede conducir a "sobreinterpretar", a estirar los textos más allá del autor, la evidencia y su contexto, como si el propio texto no existiese. Pero existe. Y más en un Derecho que es normativo, regula la realidad e impone la seguridad jurídica frente a la arbitrariedad, prevaricación y el azar.

42 Cfr. Díez Gargari (2008, p. 157) en relación con Nabokov (1997). 
Consciente de esto, entre otros, Nussbaum abomina de la sobreinterpretación y los "maliciosos errores" interpretativos señalando que hay una interpretación correcta - que no aboca ni al escepticismo ni al cientifismo (Nussbaum, 1995, p. 193 et seq.). Y es la que determina la "lectura crítica compartida" que se deriva de la co-ducción, el diálogo y el conocimiento del sentido de la vida del autor.

Ahora bien, cómo se traduce técnicamente esa clave interpretativa. Y cómo se justifica y garantiza que ese modelo interpretativo impuesto no está al servicio de un dogmatismo (Botero-Bernal, 2008, p. 63 et seq.) contrario a la autonomía racional y valorativa e imaginativa del lector, intérprete y juez ${ }^{43}$.

En cualquier caso, frente a estas cuestiones, también me importa destacar que no se trata de que la teoría literaria ya haya resuelto todos los problemas de metodología jurídica o, si no, no sirve. Sino de que arroja luz sobre campos y conceptos muy importantes del Derecho y en los que el jurista, sin duda, deberá profundizar, pero siempre aprovechando toda la luz externa que se le proponga y le haga más fácil ver, interpretar y mejorar el Derecho.

La quinta dificultad y continuación de la anterior se refiere a los límites de la teoría literaria de la interpretación frente al Derecho.

Dificultad que se proyecta en varias dimensiones de entre las que quiero destacar, por una parte, que el jurista no es un crítico literario especializado, lo que le priva de muchos instrumentos de análisis más allá de la intuición. Que el experto literario no suele ser jurista con lo que tiene muy difícil interpretar el amplio y complejo universo jurídico (Olivo; Martínez, 2014, p. 147-148). Y que ni la teoría literaria tiene un método interpretativo único, ni ha justificado su extrapolación al campo jurídico.

$\mathrm{Y}$ aquí, la propuesta literaria de la novela en cadena de Dworkin orientada a la tesis de la "única decisión jurídica correcta" tanto parece encajar en la propuesta literaria del Derecho, cuanto destaca por su originalidad, cercanía intuitiva, por su capacidad para conmover a nivel mundial la concepción metodológica iuspositivista, sea por afirmación o por negación, y por el impulso que da a la teoría de la argumentación.

43 De hecho, Hayden White, Victor Turner, Paul Ricour... centran la interpretación narrativa en la "legitimidad cultural" frente a lo diverso, lo ilegítimo (Turner, 1982). 
El problema son las debilidades y desajustes del recurso jurídicoliterario dworkiniano.

Pues, Dworkin no explica ni justifica por qué el texto jurídico debe interpretarse alejado de su autor, el legislador, especialmente si ha sido elegido democráticamente. Y tampoco ofrece razones para creer que existe un sentido trascendental entre los distintos capítulos jurídicos que permita pensar en una interpretación conclusiva verdadera, como una proyección de las pretensiones del New Criticism. Pues las respuestas más correctas penderían de justificaciones previas, epistemológicas, científicas y filosóficas. No finales, narrativas y de conclusión literaria.

De hecho, para muchos críticos literarios, ya no es solo que la teoría literaria no resuelve el problema de la interpretación, es que el New Criticism de la interpretación textual verdadera está ya fuera de juego, en la misma medida y sentido en que para un sector muy extenso de la doctrina académica y jurisprudencial la tesis principialista fuerte de Dworkin es falsa.

En sexto lugar, la dificultad por las distintas texturas y contexturas jurídica y literaria.

En concreto, se objeta la idea de que el procedimiento de análisis que vale para la literatura también es válido y adecuado en el Derecho, pues literatura y Derecho consisten en textos escritos por un emisor para un receptor - de hecho, ya se habla de la "narratología" aplicada al Derecho. Pues, con tal fundamentación cualquier amanuense, concejal y todo niño o niña capaz de unir oraciones podrían ser considerados literatos con algo que enseñar.

Esto último es problemático. Hace falta algo más para convertirse en un escritor de literatura. Igual que hay que reunir algunas condiciones más, siquiera formales, para ser un legislador o un juez. Además de que hay intenciones en quien escribe y en quien recibe lo escrito, contextos normativos, objetivos, condiciones de validez y de autoridad para dictar normas jurídicas, justificaciones, etc. que son radicalmente distintos en una y otra disciplina (Díez Gargari, 2008, p. 170-171).

Ahora bien, hay algo de sofisma y de construcción del enemigo literario a batir en tal objeción. Porque los fundamentos de la teoría 
literaria son más complejos y, ya se vio, dependen de una previa selección de textos que eviten la ceguera del enjuiciamiento binario del Derecho.

Séptimo. Frente al argumento importante de que la literatura vuelve más accesibles los contenidos jurídicos al gran público, se objeta que esa literatura diluye las condiciones técnicas del Derecho en reinos escindidos en relatos teatralizados, emocionantes, circunstanciados y sentimentales que banalizan y falsean lo jurídico y con ello la seguridad jurídica y las garantías de realización de los derechos pudiendo generar consecuencias dramáticas (Sansone, 2001, p. 109-110).

Sin embargo, creo que la objeción yerra, porque el objetivo del análisis crítico literario del Derecho no es eliminar el Derecho, sino darle más y mejor a conocer y exaltar valores y realidades que el Derecho puede desconocer gracias al instrumento universal de la literatura.

Finalmente, por todo lo anterior y a modo de conclusión.

Creo que las posibilidades literarias respecto del Derecho son muy amplias. Y que para justificar el empleo de la literatura para la deconstrucción y reconstrucción jurídica y evitar los problemas apuntados hay que definir bien los límites y contornos de la relación, lo que exige seguir profundizando en su relación recíproca, sin dar nada por asumido y evitando prejuicios. Igual que sucede, p.ej., con la controvertida relación entre la lógica formal y el Derecho.

Estoy convencida de que no hay justificación y razones para yuxtaponer o intercambiar ambas disciplinas, a pesar de lo tentador que resulten sus ciertas indeterminaciones. Y acuerdo en este punto con Posner (1988, p. 363-364); una mala comprensión de la interdisciplinariedad Derecho y literatura conduce al "amateurismo" del literato que se deja impresionar demasiado pronto por cualquier jurista o teoría jurídica, igual que el jurista cae enseguida deslumbrado por cualquier teoría o método literario de construcción y/o interpretación, y esto al margen de la relevancia que otorguen los colegas de su especialidad a tales juristas y literatos y a sus respectivas teorías.

E igualmente estoy bastante segura de que debemos ser precavidos con cómo manipulamos el conocimiento del Derecho, la técnica jurídica y la construcción de los valores de justicia e identidad. Porque aunque me parece que la oportunidad y las posibilidades de los post-positivismos, 
iuspositivismos blandos, inclusivos, llámeseles como se quiera, de los nuevos planteamientos radicales e inclusivos de la democracia, de la policentraliadad normativa, de la contradogmática de la diversidad, etc. son difícilmente contestables y que la literatura tiene mucho que ofrecerles, también soy consciente de la necesidad de técnicas de justificación argumentativa que eviten soluciones impertinentes por muy buenas que sean sus intenciones, especialmente en un campo que, como el Derecho, se caracteriza por su absoluta coactividad. Y es que, a través de los sentimientos y las emociones, igual que comprendemos más y mejor algunas cosas, también nos volvemos más vulnerables al slogan, la consigna, el sentimentalismo partidista y el interés propio y cercano.

Ahora bien, la precaución, la exigencia de límites y de justificación no restan un ápice de mi convicción en que, de un lado, la literatura ni es ni debe ser jurídicamente intrascendente, porque el valor de la imaginación, la empatía y la solidaridad es extraordinario cuando se trata de definir la justicia, los valores del Derecho en acción (Binder, 2012, p. 587-588; Posner, 1988, p. 357) y los procesos de concreción y calificación jurídica de los hechos y respecto de la norma.

$\mathrm{Y}$, de otra lado, esa literatura nos permite, tanto evitar los errores del pasado, al recordarnos de forma emotiva las injusticias, los prejuicios, el maltrato a todo tipo de personas vulnerables (Silva, Mourão, 2016, p. 369): - “¿Mi crimen? ¿Qué crimen? ¿...haber matado a un gusano venenoso, a una vieja usurera que hacía daño a todo el mundo, a un vampiro que chupaba la sangre de los necesitados? Un crimen así basta para borrar cuarenta pecados..." (Dostoievsky, Crimen y castigo). Cuanto contemplar e interpretar de forma múltiple la complejidad del Derecho, sustituyendo el servilismo a la dogmática por una visión más profunda y comprometida con la realidad social y las necesidades de las mujeres y los hombres de toda clase y condición que la integran.

\section{REFERENCIAS}

AARNIO, A. Sobre la ambigüedad semántica en la interpretación jurídica. Doxa, n. 4, p.109-117, 1987. doi: 10.14198/DOXA1987.4.07

AMAYA, A. Derecho y Literatura. In: HARO, Pedro Aullón de (Coord.). Metodologías comparatistas y literatura comparada. Madrid: Dykinson, 2013. p. 173-182. 
BELLOW, G.; MINOW, M. Law stories. Ann Arbor: University of Michigan Press, 1998.

BINDER, G. Law and Literature. Buffalo Legal Studies Research Paper, n. 22, p. 585-592, 2012.

BINDER, G.; WEISBERG, R. Literary Criticism of Law. Princenton: Princenton University Press, 2000.

BONORINO, P. R. Sobre el uso de la literatura en la enseñanza del Derecho. REJIE - Revista Jurídica de Investigación e Innovación Educativa, n. 4, p. 73-90, 2011.

BOTERO-BERNAL, A. Derecho y literatura: un nuevo modelo para armar. Instrucciones de uso. In: CALVO GONZÁLEZ (Dir.). Implicación Derecho Literatura: contribuciones a una Teoría del Derecho. Granada: Comares, 2008. p. 29-39.

BROOKS, P. The Law as Narrative and Rethoric. In: BROOKS, P.; GEWIRTZ, P. (Comp.). Law's Stories: Narrative and Rethoric in the Law. New Haven: Yale University Press, 1996. p. 14-22.

BRUNER, J. The narrative construction of reality. Critical Inquiry, v. 18, n. 1, p. 1-21, 1991. Disponible en: $<$ http://www.semiootika.ee/sygiskool/tekstid/bruner.pdf $>$. Acceso en: 25 abr. 2017.

CALVO GONZÁLEZ, J. Teoría literaria del Derecho. Derecho y literatura: intersecciones instrumental, estructural e institucional. In: FABRA ZAMORA, J. L.; NÚÑEZ VAQUERO, A. (Ed.). Enciclopedia de Filosofia y teoría del derecho; 1. México: UMAN, 2015. p. 695-736. Disponible en: $<$ http://biblio.juridicas.unam.mx/libros/8/3875/22.pdf $>$. Acceso en: 25 abr. 2017.

CALVO GONZÁLEZ, J. De la Ley ¿O será ficción? Madrid: Marcial Pons, 2016.

CÁRCOVA, C. M. Derecho, literatura y conocimiento. Revista Jurídica de Buenos Aires, n. 198, 2000. Disponible en: <http://www.pensamientocivil.com.ar/doctrina/81-derecho-literatura-yconocimiento $>$. Acceso en: 25 abr. 2017.

CARDOZO, B. Law and Literature. New York: Harcourt, Brace \& Comp., 1931.

CARRERAS, M. Derecho y literatura. Persona y derecho - Revista de fundamentación de las Instituciones Jurídicas y de Derechos Humanos, n. 34, p. 33-62, 1996. Disponible en: <http://hdl.handle.net/10171/12885>. Acceso en: 25 abr. 2017.

CASTORIADIS, C. L'Institution imaginarire de la société. Paris: Seuil, 1975 .

CONTI, D. B. Narrative theory and the Law. Duquesne Law Review, n. 39, p. 457-476, 2000.

CRAFT, G. A. The persistence of dread in Law and literature. Yale Law Journal, v. 102, n. 2, p. 521-546, 1992. 
DÍEZ GARGARI, R. Dejemos en paz a la literatura. Isonomía, v. 29, p. 149176, 2008.

DUARTE, C. B.; MADERS, A. M. O direito e literatura cruzando os caminhos da justicia poética: uma estrada sem fim? Anais do IVCIDIL, v. 1, p. 162-181, 2016. Disponible en: <http://rdl.org.br/seer/index.php/anacidil/article/view/103/296>. Acceso en: 25 abr. 2017.

DWORKIN, R. My Reply to Stanley Fish (and Walter Benn Benjamin): Please don't Talk about Objectivity Anymore. In: MITCHELL, W. J. T. (Ed). The Politics of Interpretation. Chicago: University of Chicago, 1983 . p. 271286.

EAGLETON, T. Literary Theory: An Introduction. Oxford: Basil Blackwell, 1983 .

EAGLETON, T. La rebelión del lector. Revista Punto de Vista, n. 24, p. 1213,1985 .

FALCÓN Y TELLA, M. J. Derecho y Literatura. Madrid: Marcial Pons, 2015.

FISH, S. Is there a text in this class?: the authority of interpretivecommunities. Cambridge: Harvard University Press, 1980.

FISH, S. Working on the Chain Gang: Interpretation in the Law and Literary criticism. Critical Inquiry, v. 9, n. 1, p. 201-216, 1982.

FISH, S. Wrong Again. Texas Law Review, n. 62, p. 299-316, 1983.

FISH, S. Still Wrong after All these Years. Law and Philosophy, v. 6, n. 3 p. 401-418, 1987a.

FISH, S. Denis Martínez and the Uses of Theory. The Yale Law Journal, v. 96, p. 1773-1800, 1987b.

FREITAS, R. Barradas de. Direito, linguagem e literatura: reflexões sobre o sentido e alcance das inter-relações. Working Paper, Universidade Nova de Lisboa, v. 6, n. 2, 2002. Disponible en: < http://www.fd.unl.pt/Anexos/Downloads/235.pdf $>$. Acceso en: 25 abr. 2017.

FRUG, J. Argument as character. Standford Law Review, n. 40, p. 867927, 1988.

GARCÍA AMADO. J. A. Breve introducción sobre Derecho y literatura. In: GARCÍA AMADO. J. A. Ensayos de Filosofía Jurídica. Bogotá: Temis, 2003. p. 361-371.

GARCÍA VALVERDE. F. Desacuerdo moral y estabilidad en la teoría de Martha Nussbaum. Revista de filosofía y teoría política, n. 40, p. 63-90, 2009.

HAYMAN, R. L.; LEVIT, N.; DELGADO; R. Jurisprudence, Classical and Contemporary: From Natural Law to Postmodernism. St. Paul: West Academic Publishing, 2002.

ISER, W. The Implied Reader: Patterns of Communication in Prose Fiction from Bunyan to Beckett. Baltimore: Johns Hopkins University Press, 1974. 
KADOCH, L. C. Seduced by narrative: persuasion in the courtroom. Drake Law Review, v. 49, p. 71-123, 2000.

MACCORMICK, N. Coherence in legal justification. In: KRAVIETZ, W. et al. (Ed.). Theorie der Normen. Berlin: Duncker \& Humblot, 1984. p. 37-53.

MACCORMICK, N. Rhetoric and The Rule of Law: A Theory of Legal Reasoning. Oxford: Oxford University Press. 2005.

NABOKOV, V. Curso de Literatura Europea. Madrid: Grupo Zeta, 1997.

NUSSBAUM. M. Poetic Justice: The literary Imagination and the Public Life. Boston: Bacon Press, 1995.

OLIVO, L. C. Cancellier; MARTÍNEZ, R. Oliveira. Direito, literatura e cinema: o movimento direito e literatura como modelo teórico para os estudos Direito e Cinema. Anais do II CIDIL, p. 144-165, 2014. Disponible en: $\quad$ http://rdl.org.br/seer/index.php/anacidil/article/view/177/271 $>$. Acceso en: 25 abr. 2017.

OLSEN, S. H. The structure of literary understanding. Cambridge: Cambridge University Press, 1978.

OST, F. El reflejo del Derecho en la literatura. Doxa, v. 29, p. 333-348, 2006. doi: 10.14198/DOXA2006.29.17

PÊPE, A. M. Bastos 2016. Direito e literatura: uma intersecção possível? Interlocuções com o pensamento waratiano. Anamorphosis - Revista Internacional de Direito e Literatura, v. 2, n. 1, p. 5-15, 2016. doi: 10.21119/anamps.21.5-15

PEREDA, C. Sobre la retórica. In: HERRERA, M. (Coord.). Teorías de la Interpretación. Ensayos sobre Filosofía, Arte y Literatura. México: UNAM, 1998. p. 103-124.

POSNER, R. Law and Literature. A Misunderstood Relation. Cambridge (MA); London: Harvard Univesity Press, 1988.

RÍOS, C. La Literatura y el cine como herramientas para la formación ética de los jueces. Isonomía, v. 22, p. 207-219, 2005.

RORTY, R. Objetivity, Relativism and Truth. Cambridge: Cambridge University Press, 1991.

RORTY, R. Filosofía y Futuro. Barcelona: Gedisa, 2002.

SANSONE, P. Diritto e letteratura. Un'introduzione generale. Milano: Giuffré, 2001.

SEATON, J. Law and literature: works, criticism, and theory. Yale Journal of Law \& the Humanities, v. 11, n. 2, p. 479-507, 1999.

SILVA, Ana Isabel Gama. O conceito de Justiça Poética em Martha Nussbaum. Dissertação (Mestrado em Estética e Filosofia da Arte)Faculdade de Letras, Universidade de Lisboa, Lisboa, 2006. Disponible en: $<$ http://revistaphilosophica.weebly.com/2007.html >. Acceso en: 19 sept. 2015.

SILVA, F. Pessoa da; MOURÃO, R. C. A literatura como fonte de reflexão crítica do direito. Anais do IV CIDIL, v. 2, p. 356-370, 2016. Disponible en: 
$<$ http://rdl.org.br/seer/index.php/anacidil/article/view/113/308 >. Acceso en: 25 abr. 2017.

SILVA, J. Aguiar e. A prática judiciária entre direito e literatura. Coimbra: Almedina, 2001.

STRATTON, A. M. Courtroom narrative and finding of fact: reconstruct the past one (cinder) block at time. Quinnipiac Law Review, v. 22, n. 4, p. 923946, 2004.

SUÁREZ LLANOS, L. La cultura jurídica y el pluralismo jurídico. Boletín de la Facultad de Derecho, v. 24, p. 15-57, 2004.

TALAVERA, P. Derecho y Literatura. Granada: Comares, 2006.

TALAVERA, P. Una aproximación literaria a la relación entre justicia y derecho. Anamorphis - Revista Internacional de Direito e Literatura, v. 1, n. 2, p. 207-246, 2015. doi: 10.21119/anamps.12.207-246

TRINDADE, A. Karam; GUBERT, R. M. Derecho y literatura acercamientos y perspectivas para repensar el derecho. Instituto de Investigaciones Ambrosio L. Gioja, v. 3, n. 4, p. 164-213, 2009.

TURNER, V. From Ritual to Theatre: The Human Seriousness of Play. New York: Performing Arts Journal Publications, 1982.

WARD, I. Text, author and literature in legal studies. In: WARD, I. Law and Literature. Possibilities and Perspectives. Cambridge: Cambridge University Press, 1995. p. 28-42.

WARD, I. Littérature et imaginaire juridique. Revue interdisciplinaire d'études juridiques, n. 42, p. 161-179, 1999.

WEISBERG, R. The Law-literature Enterprise. The Yale Journal of Law \& Human, n. 1, p. 1-67, 1988.

WEST, R. Economic Man and Literary Woman: One Contrast. Mercer Law Review, v. 39, p. 867-878, 1988a.

WEST, R. Communities, Texts, and Law: Reflections on the Law and Literature Movement. Yale Journal of Law and Humanities, v. 1, n. 1, p. 129-156, 1988b.

WHITE, J. B. The Legal Imagination: Studies in the Nature of the Legal Thought and Expression. Boston; Toronto: Little, Brown \& Co., 1973.

WHITE, J. B. Law as Rhetoric, Rhetoric as Law. University of Chicago Law Review, v. 52, n. 3, p. 684-702, 1985a.

WHITE, J. Boyd. Heracles' Bow: Essays on the Rhetorie and Poetry of Law. Madison: The University of Wisconsin Press, 1985b.

WHITE, J. B. Justice as Translation: An Essay in Cultural and Legal Criticism. Chicago: University of Chicago Law Review, 1990.

WHITE, J. B. From Expectation to Experience. Ann Arbor: University of Michigan Press, 2000. 
WIGMORE, J. A list of legal novels. Illinos Law Review, v. 2, n. 9, p. 574593, Apr. 1908.

ZOLEZZI IBÁRCENA, L. Derecho y literatura: aspectos teóricos. Derecho PUCP, n. 70, p. 379-409, 2013.

Lengua original: Español

Recibido: 05/06/17

Aceptado: 10/11/17 